\title{
Dipping 1200 toes into the pool of immersive interaction design
}

\author{
Jonathan Hamilton \\ Senior Lecturer, Ba/Ma Graphic Design, Nottingham Trent University \\ Room 329 Bonington Building Ba Graphic Design, School of Art and Design \\ The Nottingham Trent School of Art and Design Bonington Building ,Burton Street ,Nottingham ,NG1 4BU \\ jonathan.hamilton@ntu.ac.uk
}

This paper and presentation centres around a case study of the last two years of an interactive project with second year BA Graphic Design students lead by Jonathan Hamilton. The project was concerned with "How (in five weeks) do you teach immersive interaction design to a cohort of 120 students who are new to interactive design?"

The project aims were

- To give students both an understanding of professional interactive design and working methods

- To manage the process of design within a medium sized group

- $\quad$ To design with an understanding of the wider possibilities for interactivity beyond the typical small screen website on a desktop.

- To consider appropriate thematic visual approaches to interface design.

The presentation will demonstrate through the interactive project blog some of the past student blogs ; a range of methods used for group design including the use of large sheets, speed networking, site user analysis, user testing and feedback, and a range of experimental and visually rich interface design experiences. The presentation will show some of this vibrant visual student design work by demonstrating their interactive project work live, giving a immersive thematic experience for the audience. The project started in its original format five years ago. Reference will be made to the pattern of change over this period. Immersivity Interface Design Collaborative Group

\section{THE INTERACTIVE PROJECT}

The interactive project for second year Nottingham Trent University (NTU) BA Graphic Design students has taken a variety of forms over the last four years. As cohort sizes grew from 70 to 120 , from 700 toes to 1200 toes. The project was a compulsory group project. When cohorts were 70 students would all participate in one five week period simultaneously .As the cohort grew the year split and rotated through a five-week print project and a five-week interactive project

The course at NTU is a broad based Graphic Design course, with no house style. For the majority of students it was their first experience of designing an interactive interface. We found that group sizes three to a maximum of four per group were ideal, any larger and sometimes not all students would participate equally.

The main aims of the project were to get students thinking more broadly about approaches to interactivity, become more confident about interaction and interface design.

The main focus of the project was for students to create an interactive project that was immersive. To be both graphically and interactively immersive. To direct their design work to immerse the user both graphically and interactively.

To achieve this a main consideration was that they should develop appropriate designed interfaces appropriate to their theme using a broad range of visual languages. Also to explore a range of interactive methods, considering size of screen. Context, audience and methods of interaction were also to be considered. Students were to consider location; was the interactive design in a quiet intimate space or busy public space?

Students were expected to design a fully resolved and designed site including a site map. But as they were new to interactive design production were not expected to make a technically fully working site.

Instead they were asked to produce a front/home page with working links to at least three parts of the site.Groups were given a broad range of themes to choose from "Signs in the city" to most recently "Worst case scenario books " "How stuff works" and "10 things you should know about...."

\subsection{Tutor contact and software}

Each week students had three days contact. A mixture of lectures, workshops and group tutorials.

Students were introduced to Dreamweaver using a range of workshops and commercial on line training videos. Some groups used elements of Flash but the main focus was Dreamweaver. Animations were often produced using Animated Gifs, as these were technically simple and quick to produce.

\subsection{The project team}

When the project originated in 2005 it ran over five to six weeks with a staff team of five. Interactive senior staff were; Joe McCullagh (now senior head of art at the University Huddersfield), Robert Newton, Jonathan Hamilton, visiting lecturer and web developer Jonny Norridge, and a screen based technician from within the department. The project in the last two years has consisted of two staff; Jonathan Hamilton and Jonny Norridge and one technician .

\subsection{Student profiles}

Many of the students were high academic achievers with a variety of backgrounds. Most have attended a one-year Art Foundation courses prior to the BA. The majority of students had good organisational skills and a professional and mature approach to their studies. There were approximately $50 \%$ male and $50 \%$ female.

\subsection{Immersive orientation}

At the start of the project students were given a list of web sites; immersive and non immersive and asked to compare and contrast the two approaches. Students were given a list of evaluation question and asked to interrogate the series of web sites with a view to understanding the range of immersive methods.

\section{GROUPS AND DESIGN}

We were aware that there was a danger of "too many cooks" with all members of the group being designers. There was the chance that they would not have been able to decide on a 
particular direction. The groups were self-governing but staff constructed sessions to allow all students to have an equal voice. In the second week in a large cohort studio environment groups were given large sheets of informal and inexpensive dot and cross paper. Students were excited by working to this large scale, breaking out of their normal graphic A4/A3 formats and found they could put all their ideas in one space. As a group they could then evaluate connections between ideas and begin to formulate a collective direction.

\subsection{Speed Networking}

To tighten up their project proposals students presented their concepts to other groups in short rotation utilising speed networking methods. Presenting their group project proposal to five other groups in succession starting with 2-minute presentations and reducing the presentation time down until the pitch became 30 seconds in duration. This helped to clarify their proposal and communication

\subsection{Student understanding}

By working in groups students had a greater collective understanding than they would on their own and understood the project requirements early on. In a project with at times complex issues with new thinking the group were collectively clear in their understanding of the project requirements.

\section{BLOGS AND GROUPS}

Five years ago we had to introduce students to the new concept of blogs. In the last 2- 3 years this has not been necessary as students are already familiar with blogs. When we first tried blogs in 2005 the student blogs were successful and the following year a project blog http://technojungle.blogspot.com/ was set up by staff. The project blog (Technojungle) shows a record of project activity; stills, video and also links to all the students project group blogs covering several years.

After this initial introduction to project blogs many students would them a useful venue.

\subsection{Group meetings and group democracy}

Each group had its own dynamic. Some groups met daily, or every few days, others met weekly.

Some groups utilised the blog extensively others less so but all groups engaged with blogging.

For many groups the blog was an essential format for discussion of ideas especially for those students who found it difficult to attend all group meetings or who were quiet or shy in group discussion. Visual work could be displayed easily and discussed by the group.

Students sometimes found that designs produced in a sketchbook context when scanned in or photographed and posted on the blog could be appear very differently. What would not have always been a project contender in the sketchbook gained more credibility and could be viewed more objectivity when seen on screen in this different context. Students who were unconfident about their work did post work on the blog and often found the group blog comments very supportive.

For some students the blog became an essential venue for design development and reflection.

Students who had found sketchbooks a less natural format found blogs a better system for developing ideas. For subsequent projects these students utilised blogs as a significant method.

\subsection{Blogs and Assessment}

Students were given an individual mark for the group project based on their contribution to the group. The main evidence would be their sketchbooks and layout sheets.

When a student's contribution to the group was in question the record of their own entries to the group blog could be used as one of the insights into their individual contributions.
Each group had their own way of dealing with the balance between technical and creative

A few groups focused too heavily on technology at the expense of fully exploiting the design and concepts but appropriate visual language was always a key feature. This helped to create an immersive experience with a particular attention to visual themeing for typography and text. Groups also made good use of looking for ways of utilising visual research in an interactive way.

\section{USER TESTING AND FEEDBACK METHODS}

Towards the end of their production phase students were introduced to the concept of user testing. The example of video game companies using games testers before releasing projects into the public domain was discussed. Some students had first or second hand experience of this role and could confirm its importance.

Groups undertook two types of user testing and feedback, written and observational. Each of the interactive projects were set up on a series of computers and groups rotated testing each other's site. Written feedback answering a questionnaire on usability, communication, immersivity, graphical language, as well as suggestions on further development.

The group also undertook observational feedback. Watching users interact with their interactive project. A rule was imposed that whilst observing; the group were to remain silent and not prompt users in any way to get a true experience of usability and communication of their project. As groups had experienced both sides of user testing it enabled them to understand the feedback more clearly.

\section{CONCLUSIONS}

We found some students produced more inventive design work when working in the group than they would normally do when working on their own. Students themselves in their reflective accounts often commented on this. The group would often encourage students to pursue initial concepts that were inventive and experimental. On their own the individual would often discard these as too risky or tangential.

We found students who in previous projects produced design work on their own with limited innovation and visual language often pursued more inventive solutions within the group than they would have otherwise. The group would encourage early stage experimental and edgy designs.

\subsection{Project feedback questionnaire}

Over the past four years at the very end of the project students have completed individual feedback questionnaires giving a record of the interactive group project over the last four years. This has helped us to refine and hone the project each year. As yet we have not analysed this data over the four-year period as a whole. This data could be useful as a record of large group interactive teaching and learning over this period of the millennium.

\subsection{Project blog}

\section{http://technojungle.blogspot.com/}

6. References

Book: Wilson, J; DeMaria,R. (2004) High Score!: The Illustrated History of Electronic Games. McGraw-Hill Publishing Co, United Kingdom.

Book:Maeda,J;Negroponte,N.(2000) Maeda@Media. Thames and Hudson, United Kingdom.

Internet source: Hi-Res!, F. (2000) http://archive.hires.net/MinorityReport/ (2010)

Internet source: Hi-Res!, F. http://www.donniedarkofilm.com/ (2010). 